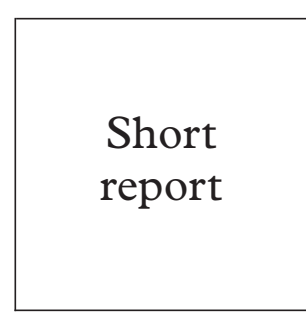

\title{
The sac-4 gene of Neisseria gonorrhoeae and co-existing chlamydial infection
}

\author{
D J Phillips, C Patrizio, A Moyes, H Young
}

Background/objectives: Recently, the sac-4 gene in Neisseria gonorrhoeae was postulated to increase the risk of developing mixed gonococcal and chlamydial infection. The aims of this study were to determine the frequency of the sac- 4 gene in a larger sample of isolates of different serovars and to assess the prevalence of sac-4 in gonococcal isolates from patients with and without coexisting chlamydial infection.

Methods: Isolates from 259 episodes of gonorrhoea were tested by a PCR assay for the sac-4 gene. The presence of co-existing chlamydial infection was determined from both laboratory and GUM clinical records.

Results: The overall prevalence of $s a c-4$ was $57.5 \%$ (149/259). The prevalence was not the same in all serovars and ranged from $34.9 \%$ in serovar $1 \mathrm{~B} 2$ to $100 \%$ in serovar 1B18. Exact logistic regression analysis indicated significant differences in sac-4 prevalence in isolates of different serovars. The prevalence of $s a c-4$ was $69.5 \%$ (41/59) in gonococcal isolates from patients with co-existing chlamydial infection compared with $57.9 \%(62 / 107)$ for those without chlamydial infection. Exact logistic regression analysis showed that the slightly increased $s a c-4$ prevalence among chlamydia positive patients $(\mathrm{p}=0.2)$ virtually disappeared when serovar status was taken into account $(\mathrm{p}>0.9)$.

Conclusion: The $s a c-4$ gene of the gonococcus does not increase the risk for mixed chlamydial infection.

(Sex Transm Inf 2000;76:400-402)

Keywords: dual infection; Neisseria gonorrhoeae; Chlamydia trachomatis; sac-4

Scottish Neisseria gonorrhoeae Reference Laboratory, Department of Medical Microbiology, Edinburgh University Medical School, Teviot

Place, Edinburgh EH8 9AG, UK

D J Phillips

C Patrizio

A Moyes

H Young

Correspondence to:

Dr Hugh Young

Hugh.Young@ed.ac.uk

Accepted for publication 18 July 2000

\section{Introduction}

Dual infection of the genital tract with Chlamydia trachomatis and Neisseria gonorrhoeae is well established with a prevalence ranging from $14-43 \%$ but little is known of the epidemiology and associated clinical features of such coexisting infections. ${ }^{1}$ Recently a gene, sac-4, was found in a high proportion of gonococcal isolates from patients with coexisting chlamydial infection and it was postulated that sac-4 increased the risk of development of mixed gonococcal and chlamydial infection. ${ }^{2}$ This gene conferred stable (not lost on subculture) complement factor $\mathrm{C} 1 \mathrm{q}$ dependent serum resistance in gonococci. ${ }^{3}$

The aims of this study were to use the polymerase chain reaction (PCR) assay described by Nowicki et $a l^{2}{ }^{3}$ to determine the

Table 1 Sac-4 prevalence in various gonococcal serovars isolated from patients with and without coexisting chlamydial infection

\begin{tabular}{llll}
\hline \multicolumn{4}{c}{ Sac-4 $4^{+}$prevalence } \\
\cline { 2 - 4 } Serovar & Overall & $\begin{array}{l}\text { Known chlamydia } \\
\text { positive patients }\end{array}$ & $\begin{array}{l}\text { Known chlamydia } \\
\text { negative patients }\end{array}$ \\
\hline 1A2 & $80 \%(20 / 25)$ & $69.2 \%(9 / 13)$ & $100 \%(5 / 5)$ \\
Other 1At & $44.5 \%(8 / 18)$ & $40 \%(2 / 5)$ & $57 \%(4 / 7)$ \\
1B2 & $34.9 \%(22 / 63)$ & $42.9 \%(3 / 7)$ & $32.1 \%(9 / 28)$ \\
1B3 & $63.3 \%(19 / 30)$ & $60 \%(6 / 10)$ & $71.4 \%(10 / 14)$ \\
1B6 & $42.6 \%(20 / 47)$ & $50 \%(1 / 2)$ & $40.9 \%(9 / 22)$ \\
1B18 & $100 \%(16 / 16)$ & $100 \%(7 / 7)$ & $100 \%(8 / 8)$ \\
1B31 & $91.7 \%(33 / 36)$ & $100 \%(8 / 8)$ & $93.8 \%(15 / 16)$ \\
Other 1B $\ddagger$ & $45.8 \%(11 / 24)$ & $71.4 \%(5 / 7)$ & $28.6 \%(2 / 7)$ \\
Total & $57.5 \%(149 / 259)$ & $69.5 \%(41 / 59)$ & $57.9 \%(62 / 107)$ \\
\hline
\end{tabular}

*Chlamydia status was not known for 93 patients.

$\dagger 18$ isolates representing serovars $1 \mathrm{~A} 1,1 \mathrm{~A} 4,1 \mathrm{~A} 5,1 \mathrm{~A} 6,1 \mathrm{~A} 8$, and $1 \mathrm{~A} 21$.

$\ddagger 24$ isolates representing serovars $1 \mathrm{~B} 1,1 \mathrm{~B} 4,1 \mathrm{~B} 7,1 \mathrm{~B} 8,1 \mathrm{~B} 13,1 \mathrm{~B} 23$, and $1 \mathrm{~B} 32$. frequency of the sac-4 gene in a larger range of isolates of different serovars; and to assess the prevalence of sac-4 in gonococcal isolates from patients with and without coexisting chlamydial infection.

\section{Materials and methods}

PATIENTS AND ISOLATES

Isolates from 259 episodes of gonorrhoea in 80 female and 179 male patients attending a genitourinary medicine (GUM) clinic were studied. The isolates represented 19 different serovars. The prevalence of sac-4 was determined for each of the common serovars, arbitrarily defined as comprising more than 15 isolates each: serovars represented by less than 15 isolates were grouped together as "other $1 \mathrm{~A}$ " and "other 1B" serovars (see table 1 ). The presence of coexisting chlamydial infection was determined from laboratory and GUM clinical records.

\section{EXTRACTION OF DNA AND PCR ASSAY}

The growth from an overnight plate culture was mixed with $1 \mathrm{ml}$ of saline, centrifuged, resuspended in $200 \mu \mathrm{l}$ of distilled water, and heated for 20 minutes at $100^{\circ} \mathrm{C}$. After cooling and centrifugation the supernatant from each tube was stored at $-20^{\circ} \mathrm{C}$ for PCR testing.

Primers were as described by Nowicki et $a l^{4}$ : Primer A, 5' TAT CTG CAG CAT CTC CTT TCC AAC C 3' Primer B, 5' TAG GAA TTC CTC TGA AGG TTA CGG 3'. 

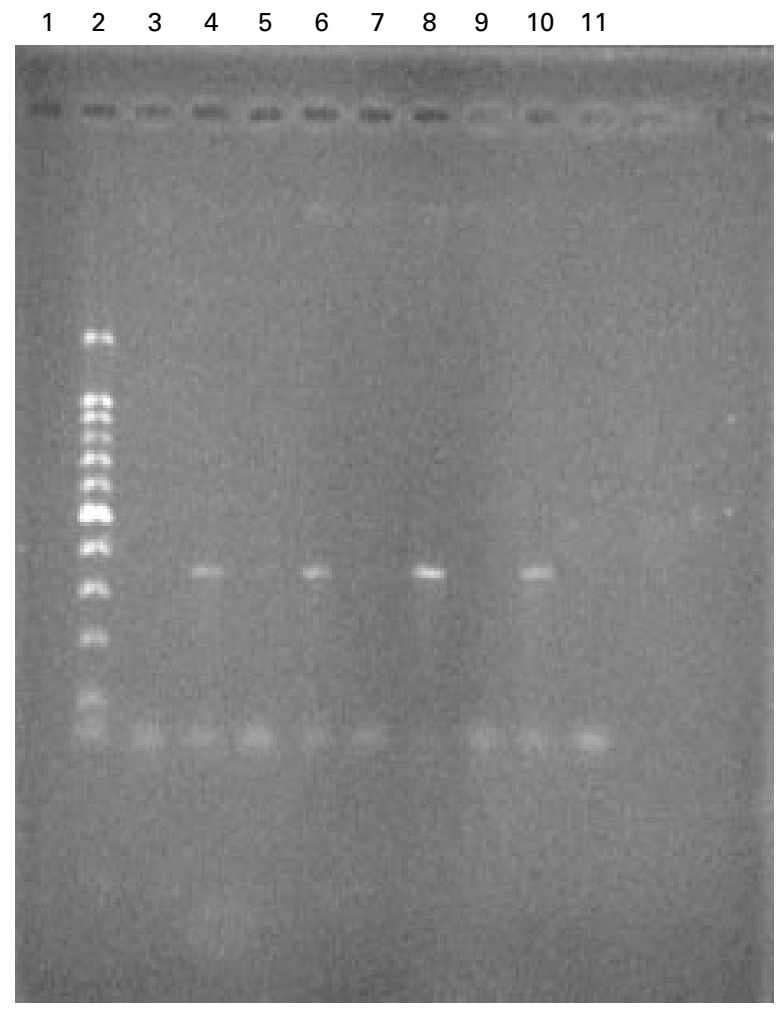

Figure 1 A typical gel showing products from the PCR assay for the sac-4 gene of Neisseria gonorrhoeae. Lane 1, blank; lane 2, DNA ladder; lane 3, negative control strain

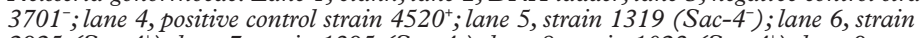
2925 (Sac-4 $4^{+}$; lane 7, strain 1395 (Sac-4-4); lane 8, strain $1023\left(\right.$ Sac-4 $\left.{ }^{+}\right)$; lane 9, strain 3256 (Sac-4); ;ane 10, strain 4098 (Sac-4) ; lane 11, strain $2850\left(\right.$ Sac-4 $\left.^{-}\right)$.

A volume of $2 \mu \mathrm{l}$ of DNA template was added to $100 \mu$ reaction $\operatorname{mix}(50 \mathrm{mM} \mathrm{KCl}, 10$ $\mathrm{mM}$ TRIS-HCl, $15 \mathrm{mM} \mathrm{MgCl}_{2}$ and $0.1 \%$ Triton $\mathrm{X}-100)$ containing 0.5 units of Taq Polymerase (Promeg Corporation, Southampton), $20 \mu \mathrm{mol}$ of each DNTP (Promega), and $0.1 \mu \mathrm{mol}$ of each primer (Oswel DNA Service, Southampton). The reaction mixture was overlaid with two drops of liquid paraffin. The amplification reaction consisted of 30 cycles of 1 minute denaturation at $92^{\circ} \mathrm{C}, 1$ minute annealing at $55^{\circ} \mathrm{C}$, and 1 minute extension at $72^{\circ} \mathrm{C}$. An aliquot of $20 \mu \mathrm{l}$ was removed for electrophoretic analysis on a $2 \%$ agarose gel. A band corresponding to 344 base pairs indicated a positive $s a c-4$ result.

A sac-4 negative and positive control strain were included in each run.

STATISTICAL ANALYSIS

This was performed using exact logistic regression.

\section{Results}

PCR analysis showed that 149 isolates $(57.5 \%)$ were $\mathrm{sac}-4^{+}$(each strain gave a single band corresponding to 344 base pairs) and 110 isolates $(42.5 \%)$ were $s a c-4^{-}$(no bands present). An example of a typical gel is shown in figure 1 . The prevalence of sac-4 ranged from $34.9 \%$ in serovar $1 \mathrm{~B} 2$ to $100 \%$ in serovar $1 \mathrm{~B} 18$ (table 1 ). The data in table 1 were analysed by exact logistic regression, with $s a c-4$ as the response (dependent) variable, and chlamydia status and gonococcal serovar as independent (ex- planatory) factors with two and eight levels respectively. Comparing chlamydia positive with chlamydia negative patients unadjusted for serovar gave an odds ratio $=1.65$, CI $(0.8,3.47) \mathrm{p}=0.2$. This indicates that overall a higher prevalence of sac-4 was observed in gonococcal isolates from chlamydia positive patients than in isolates from chlamydia negative patients but the difference was not statistically significant. Comparing the prevalence of sac-4 in gonococcal isolates from chlamydia positive patients with chlamydia negative patients adjusted for gonococcal serovar gave an odds ratio $=1.06 \mathrm{CI}(0.42,2.6)$ $\mathrm{p}>0.9$. Thus the slight excess of $s a c-4$ prevalence in gonococcal isolates from chlamydia positive patients virtually disappears when the serovar of the infecting gonococcal isolate is taken into account.

Comparing the effects of gonococcal serovar adjusted for the chlamydia status of the patient, the odds ratios compared with serovar 1A2 were: other 1A serovars $0.19 \mathrm{CI}$ (0.01-1.44); $1 \mathrm{~B} 20.14 \mathrm{CI}(0.01-0.74)$; $1 \mathrm{~B} 30.44 \mathrm{CI}(0.06-$ 2.29); 1B6 0.11 CI (0.002-1.06); 1B18 undefined (this group had $100 \%$ prevalence for sac4); 1B31 4.34 CI 0.32-251.66); other 1B 0.33 (0.05-1.84). These results indicate significant differences in sac-4 prevalence between the serovar groups taking into account the chlamydia status of the patients. Exact logistic regression analysis for interaction between chlamydia status and gonococcal serovar yielded a $p$ value of 0.05 . Thus there is no evidence for differences between serovar groups in the comparison of sac- 4 prevalences between the chlamydia positive and chlamydia negative patients.

Similar results were obtained using approximate logistic regression including the subjects with unknown chlamydia status.

\section{Discussion}

The majority of isolates, $57.5 \%(149 / 259)$ in our local population of gonococci, were $s a c-4$ positive. However, the prevalence of $s a c-4$ was not significantly higher $(p=0.2)$ in gonococcal isolates from patients with coexisting chlamydial infection $(69.5 \%)$ than in those without $(57.9 \%)$. These findings suggest that sac-4 does not increase the risk of developing mixed infection with $C$ trachomatis. Our findings differ from those of Nowicki et al who found sac-4 in $71 \%(10 / 14)$ of gonococcal strains isolated from patients with mixed gonococcal and chlamydial infection and $7 \%(1 / 14)$ in isolates from patients with gonococcal infection only. Using exact logistic regression analysis we have shown that there are significant differences in the prevalence of $s a c-4$ between certain serovars.

Both epidemiological and biological factors may play a part in the occurrence of coexisting gonococcal and chlamydial infection. However our findings do not support a biological role for $s a c-4$ in the development of mixed infection.

We are grateful to Hannah Wills for checking records for coexisting gonococcal and chlamydial infections and to Dr John Duffy, director of Statlab Statistical Laboratory, Department of 
Mathematics and Statistics, University of Edinburgh for performing the statistical analysis.

Contributors: The study was designed by HY; CP set up the sac-4 PCR assay in the laboratory; DJP performed sac-4 testing of the isolates; AM performed serotyping and provided valuable comments in the development of the manuscript; DJP and HY were responsible for the analysis of the data and preparation of the manuscript.

1 Matando P, Johnson I, Sivapalan S. Epidemiology and transmission patterns of concomitant genital chlamydial
and gonococcal infections. Genitourin Med 1995;71:266-7.
2 Nowicki S, Hart A, Anderson GD, et al. Relationship between chlamydial co-infection and C1q-dependent Qum resistance of Neisseria Quentin-Millet MJ, Taha M-K, eds. Abstracts Of The Eleventh International Pathogenic Neisseria Conference. Paris: EDK, 1998:81

3 Nowicki S, Prashanth R, Pham T, et al. Pelvic inflammatory disease isolates of Neisseria gonorrhoeae are distinguished by $\mathrm{C} 1 \mathrm{q}$-dependent virulence for newborn rats and by the sac-4 region. Infect Immun 1997;65:2094-9.

4 Nowicki S, Martens MG, Nowicki BJ. Gonococcal infection in a non-human host is determined by human complement C1q. Infect Immun 1995;63:4790-4. 